\title{
ANALISIS DAN DESAIN SISTEM PENDUKUNG KEPUTUSAN PENENTUAN DOSEN PEMBIMBING TUGAS AKHIR MENGGUNAKAN METODE AHP
}

\author{
Weda Adistianaya Dewa ${ }^{1)}$, Linda Suvi Rahmawati ${ }^{2)}$ \\ ${ }^{1,2}$ Sistem Informasi STMIK PPKIA Pradnya Paramita \\ Email: wedadewa25@gmail.com ${ }^{1)}$
}

\begin{abstract}
ABSTRAK
Dalam penentuan dosen pembimbing tugas akhir dalam pengambilan keputusan oleh program studi di STMIK PPKIA Pradnya Paramita terdapat beberapa faktor yang menjadi penilaian. Penilaian ini berdasarkan 5 kriteria yakni tingkat pendidikan, road map penelitian dosen, latar belakang, bidang minat, dan jabatan fungsional. Demi efisiensi dan efektifitas program studi maka pengambilan keputusan yang tepat sangat diperlukan. Penelitian tersebut digunakan untuk membangun sebuah sistem pengambilan keputusan yang mempunyai kemampuan menganalisa penentuan dosen pembimbing tugas akhir dengan menggunakan metode AHP, dimana masingmasing kriteria dalam hal ini faktor-faktor penilaian dan alternatif dosen pembimbing dibandingkan satu dengan yang lainnya sehingga memberikan output nilai intensitas prioritas yang menghasilkan suatu system yang memberikan penilaian terhadap setiap dosen pembimbing. Sistem pengambilan keputusan ini dapat membantu program studi dalam menentukan dosen pembimbing tugas akhir berdasarkan kriteria dan nilai pembobotan. Hal ini berguna untuk memudahkan pengambilan keputusan yang terkait dengan penentuan dosen pembimbing, sehingga akan didapatkan dosen pembimbing tugas akhir yang paling layak untuk membimbing mahasiswa sesuai core kompetensi program studi.
\end{abstract}

\section{Kata Kunci: Metode AHP, Pengambilan keputusan, Penentuan Dosen Pembimbing Tugas Akhir.}

\section{ABSTRACT}

The supervisor in the final assignment as a result of the study program at STMIK PPKIA Pradnya Paramita there were several factors that became facts. This assessment is based on five levels of education, research roadmap, background, areas of interest, and functionality. For the sake of efficiency and effectiveness of study programs, the right decision is needed. The research is to build a system that produces decisions that allow you to analyze the cost of loading using the AHP method, where each source in this factor is the main and alternative factors that can be used to produce output. The system that raises a system that provides information for the supervisor. This decision-making system can help the study program in issuing the final assignment supervisor based on criteria and weighting values. This is useful to provide the results needed with the supervisor so that it will produce a very appropriate loading to guide students according to the core of the study program.

Keywords: AHP method, Result Taking, Determination of Final Assignment Lecturer.

\section{PENDAHULUAN}

\subsection{Latar Belakang}

Tugas akhir adalah suatu karya ilmiah berdasarkan kegiatan mandiri mahasiswa berupa hasil penelitian yang membahas suatu masalah yang sesuai dengan bidang ilmu pada program studi yang ditempuh oleh mahasiswa dengan menggunakan aturan yang berlaku di sekolah tinggi dan dibimbing oleh dosen pembimbing. Mahasiswa akan melakukan bimbingan dengan dosen pembimbing tugas akhir selama proses pengerjaan tugas akhir minimal melaksanakan pembimbingan atau konsultasi dengan dosen pembimbing minimal 8 kali pembimbingan. Dosen pembimbing tugas akhir memiliki peran penting karena memiliki tanggung jawab untuk memastikan bahwa mahasiswa mampu menyusun tugas akhir dengan baik hingga tugas akhir tersebut siap diujikan dan berkualitas. Peranan dosen pembimbing tugas akhir secara garis besarnya: sebagai organisator, fasilitator, inovator, teladan, evaluator, konselor, motivator dan pemberi energi. Dalam Permendikbud nomor 49 tahun 2014 tentang Standar Nasional Pendidikan Tinggi, UndangUndang Republik Indonesia nomor 14 tahun 2005 tentang Guru dan Dosen, Permenpan No 17 tahun 2013 Lampiran $\mathrm{V}$, tentang tugas wewenang dan tanggung jawab mengajar program studi serta aturan yang berlaku di internal yang merupakan acuan atau pedoman yang harus dimiliki oleh sekolah tinggi. Oleh karena itu, penentuan dosen pembimbing tugas akhir juga memiliki faktor penting terutama yang berkaitan dengan core kompetensi program studi karena akan berpengaruh terhadap bimbingan yang akan dilakukan oleh mahasiswa selama proses pengerjaan tugas akhir. 
Seorang Mahasiswa bisa dikatakan lulus jika sudah menempuh seluruh matakuliah wajib yang ada, salah satu matakuliah wajib tersebut adalah Tugas Akhir untuk mahasiswa berjenjang Diploma dan Skripsi untuk mahasiswa yang menempuh pendidikan jenjang Sarjana. Untuk menempuh matakuliah tersebut ada beberapa tahapan, mulai dari penentuan judul, pemilihan dosen pembimbing, seminar judul, bimbingan, dan ujian sidang. Pada tahap penentuan dosen pembimbing, mahasiswa dapat memilih dari daftar dosen yang telah ditentukan oleh bagian akademik, akan tetapi tidak semua mahasiswa mendapatkan dosen pembimbing yang sesuai dengan pilihannya. Hal ini dikarenakan dalam penentuan dosen pembimbing pada program studi institusi belum memiliki road map penelitian dan masih berdasarkan subjektifitas, sehingga menyebabkan topik yang diusulkan mahasiswa tidak sesuai dengan bidang keahlian dosen serta tugas akhir yang dihasilkan mahasiswa tidak sesuai dengan core kompetensi program studi.

Sistem Pendukung Keputusan (Decision Suport Sistem) merupakan sistem informasi interaktif yang menyediakan informasi, pemodelan, dan pemanipulasian data. Sistem ini digunakan untuk membantu pengambilan keputusan dalam situasi yang semiterstruktur dan situasi yang tidak terstruktur, dimana tidak seorang pun tahu secara pasti bagaimana keputusan seharusnya dibuat. Menurut L, Saaty The Analytic Hierarchy Process (AHP)adalah teori pengukuran melalui perbandingan berpasangan dan bergantung pada penilaian ahli untuk menurunkan skala prioritas. Pengukuran skala relatif berbentuk kualitatif. Perbandingan menggunakan penilaian yang mutlak dan dibandingkan antara satu elemen dengan elemen lainnya.

AHP melakukan analitis prioritas kriteria dengan metode perbandingan berpasangan antar dua kriteria hingga semua kriteria yang ada tercakup. Prioritas ini ditentukan berdasarkan pandangan para pakar dan pihak-pihak yang berkepentingan terhadap pengambilan keputusan. Ada 5 kriteria yang digunakan dalam Penentuan Dosen Pembimbing Tugas Akhir ini, yaitu tingkat pendidikan, roadmap penelitian dosen, latar belakang, bidang minat, dan jabatan fungsional.

Dengan adanya permasalahan tersebut maka diperlukannya sebuah Aplikasi Pengambilan Keputusan untuk penentuan dosen pembimbing menggunakan metode AHP. Dengan adanya standar penentuan dosen pembimbing tersebut dapat memudahkan program studi dan lebih bijak dalam menentukan dosen pembimbing yang sesuai dengan judul yang diajukan oleh mahasiswa sehingga core kompetensi program studi dapat tercapai.

\subsection{Rumusan Masalah}

Berdasarkan uraian dari latar belakang di atas maka dapat dirumuskan masalah yang timbul pada objek penelitian adalah "Bagaimana membangun Sistem Pendukung Keputusan penentuan Dosen Pembimbing Tugas Akhir menggunakan metode Analytical Hierarchy Process (AHP) di STMIK PPKIA Pradnya Paramita Malang."

\subsection{Tujuan Penelitian}

Tujuan yang akan dicapai adalah terbangunnya Sistem Pendukung Keputusan penentuan Dosen Pembimbing Tugas Akhir menggunakan metode Analytical Hierarchy Process (AHP) di STMIK PPKIA Pradnya Paramita Malang.

\section{METODE PENELITIAN}

\subsection{Landasan Teori}

Konsep utama dari "Sistem Pendukung Keputusan/Decision Support Sistem (DSS) yang mendefenisikan DSS suatu sistem interaktif yang berbasiskan komputer yang membantu pengambilan keputusan dengan menggunakan data dan model untuk memecahkan masalah yang tidak terstruktur" (Mardison, 2012).

Definisi DSS adalah "gabungan sumber daya individual yang intelektual dengan kemampuan komputer untuk meningkatkan kualitas keputusan yang diambil yaitu sebuah sistem yang dibantu oleh komputer untuk pembuatan keputusan yang berhubungan dengan masalah semi terstruktur" (Mardison, 2012).

SPK merupakan sistem informasi interaktif yang menyediakan informasi, pemodelan, dan pemanipulasian data. Sistem itu digunakan untuk membantu pengambilan keputusan dalam situasi yang semi terstruktur dan situasi yang tidak terstruktur, dimana tak seorang pun tahu secara pasti bagaimana keputusan seharusnya dibuat (Kusrini, 2007). Tersedia penyimpanan data dan retrieval, tetapi meningkatkan akses informasi tradisional dan fungsi pengambilan dengan dukungan pembangunan model dan model berbasis penalaran. Dalam hal ini cara kerja sistem pengambilan keputusan/ Decision Support Sistem (DSS) dapat ditunjukkan pada Gambar 1.

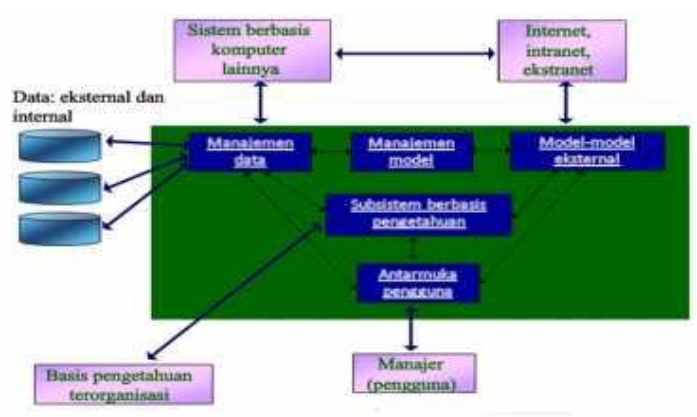

Gambar. 1 cara kerja system pengambilan keputusan

Metode Analytical Hierrchy Process (AHP) dekembangkan oleh Prof. Thomas Lorie Saaty dari Wharton Business School di awal tahun 1970, yang 
digunakan untuk mencari rangking atau urutan prioritas dari berbagai alternatif dalam pemecahan suatu permasalahan (Sinaga \& Hasan, 2015). Dalam kehidupan sehari hari, seseorang senantiasa dihadapkan untuk melakukan pilihan dari berbagai alternatif. Disini diperlukan penentuan prioritas dan uji konsistensi terhadap pilihan-pilihan yang telah dilakukan. Dalam situasi yang kompleks, pengambilan keputusan $\mathrm{t}$ idak dipengaruhi oleh satu faktor saja melainkan multifaktor dan mencakup berbagai jenjang maupun kepentingan. Pada dasarnya AHP adalah suatu teori umum tentang pengukuran yang digunakan untuk menemukan skala rasio, baik dari perbandingan berpasangan yang diskrit maupun kontinu. Perbandingan-perbandingan ini dapat diambil dari ukuran aktual atau skala dasar yang mencerminkan kekuatan perasaan dan preferensi relatif.

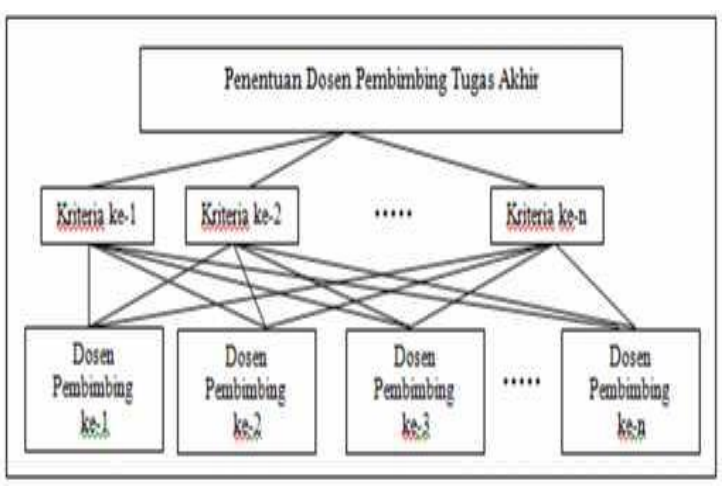

Gambar. 2 Struktur Hirarki Pengambilan Keputusan Menggunakan Metode AHP

Tabel 1 Intensitas Kepentingan

\begin{tabular}{|c|c|}
\hline $\begin{array}{c}\text { Intensitas } \\
\text { Kepentingan }\end{array}$ & $\begin{array}{c}\text { Kedua Elemen sama penting dari } \\
\text { yang lainnya }\end{array}$ \\
\hline 1 & $\begin{array}{l}\text { Elemen satu sedikit lebih penting dari } \\
\text { yang lainnya }\end{array}$ \\
\hline 5 & $\begin{array}{l}\text { Elemen satu lebih penting dari yang } \\
\text { lainnya } \\
\text { Elemen satu jelas lebih penting dari } \\
\text { yang lainnya }\end{array}$ \\
\hline 9 & $\begin{array}{l}\text { Elemen Satu Mutlak penting dari } \\
\text { yang lainnya }\end{array}$ \\
\hline $2,4,6,8$ & $\begin{array}{l}\text { Nilai nilai antara dua nilai } \\
\text { pertimbangan yang berdekatan }\end{array}$ \\
\hline Kebalikan & $\begin{array}{l}\text { Jika untuk aktifitas I mendapat satu } \\
\text { angka dibanding dengan aktifitas j, maka } \\
\text { mempunyai nilai kebalikannya } \\
\text { disbanding dengan i }\end{array}$ \\
\hline
\end{tabular}

Tahapan Analytical Hierarchy Process (AHP) merupakan penjabaran dari prinsip dasar AHP. mendefinisikan tahapan AHP adalah sebagai berikut:
1. Menganalisa permasalahan yang nyata ke dalam struktur hirarki.

2. Membuat suatu penilaian tentang kepentingan relatif antara dua elemen dan membuat matriks perbadingan berpasangan.

3. Menghitung bobot prioritas dengan cara:

a. Menjumlahkan elemen pada kolom yang sama pada matrik perbandingan yangterbentuk. Hal ini dilakukan pada setiap kolom.

b. Membagi setiap elemen pada setiap kolom dengan jumlah elemen kolomtersebut (hasil dari langkah sebelumnya). Hal ini dilakukan pada setiap kolom sehingga terbentuk matrik baru yang elemennya merupakan hasil pembagian tersebut.

c. Menjumlahkan elemen matrik baru berdasakan barisnya.

d. Membagi hasil penjumlahan baris dari langkah sebelumnya dengan totalalternatif agar didapatkan prioritas akhir tiap elemen dengan total bobot prioritassama dengan satu. Proses dilakukan untuk membuat total bobot prioritas sama dengan satu disebut proses normalisasi.

4. Menghitung konsistensi logis dengan cara:

a. Menghitung priority vektor

$$
\frac{1}{n} x\left(\sum_{i, j=0}^{n} \frac{I K_{l j}}{\text { Jumla } h_{j}}\right)
$$

b. Menghitung lamda maksimum.

$$
\lambda \max =\sum_{i=0}^{n}\left(P V_{i} x \text { jumla }_{i}\right)
$$

c. Menghitung indeks konsistensi.

$$
\mathrm{CI}=(\lambda \operatorname{maks}-n) /(n)
$$

d. Menghitung Rasio konsistensi.

$$
\mathrm{CR}=C I / I R
$$

Sistem basis data adalah sistem terkomputerisasi yang tujuan utamanya adalah memelihara data yang sudah diolah atau informasi dan membuat informasi tersedia saat dibutuhkan. Pada intinya basis data adalah media untuk menyimpan data agar dapat diakses dengan mudah dan cepat. Kebutuhan basis data dalam sistem informasi meliputi: memasukkan, menyimpan, dan mengambil data. Membuat laporan berdasarkan data yang telah disimpan (Rosa \& Shalahuddin, 2013). "Database adalah sekumpulan tabel-tabel yang berisi data dan merupakan kumpulan dari field atau kolom. Struktur file yang menyusun sebuah database adalah Data Record dan Field" (Anhar, 2010).

"MySQL adalah sebuah basis data yang mengandung satu atau jumlah tabel. Tabel terdiri atas sejumlah baris dan setiap baris menggandung satu atau sejumlah tabel (Kustiyahningsih, 2011). 
DBMS (Database Management System) atau dalam bahasa Indonesia sering sebagai Sistem Manajemen Basis Data adalah suatu sistem aplikasi yang digunakan untuk menyimpan, mengelola, dan menampilkan data. Suatu sistem aplikasi disebut DBMS jika memenuhi persyaratan minimal sebagai berikut:

- Menyediakan fasilitas untuk mengelola akses data

- Mampu menangani integritas data

- Mampu menangani akses data

- Mampu menangani backup data

Karena pentingnya data bagi suatu organisasi/perusahaan, maka hampir sebagian besar perusahaan memanfaatkan DBMS dalam mengelola data yang mereka miliki (Rosa \& Shalahuddin, 2013).

Data Flow Diagram awalnya dikembangkan oleh Chris Gane dan Trish Sarson pada tahun 1979 yang termasuk dalam Structured Systems Analiysis dan Design Methodology (SSADM ). Sistem yang dikembangkan ini berbasis pada dekomposisi fungsional dari sebuah sistem. Berikut tahapantahapan perancangan dengan mengunakan DFD :

- Membuat DFD level 0 atau sering disebut Context Diagram DFD Level 0 mengambarkan sistem yang akan dibuat sebagai suatu entitas yang berinteraksi dengan orang maupun sistem lain. DFD Level 0 digunakan untuk mengambarkan interaksi antara sistem yang akan dikembangkan dengan entitas luar.

- Membuat DFD level 1

DFD Level 1 digunakan untuk mengambarkan modul-modul yang ada dalam sistem yang akan dikembangkan. DFD Level 1 merupakan hasil breakdown DFD Level 0 yang sebelumnya sudah di buat.

- Membuat DFD Level 2

Modul-modul pada DFD Level 1 dapat di brekdown menjadi DFD level 2.

- DFD Level 3

DFD Level 3,4,5 dan seterusnya merupakan breakdown dari DFD level diatasnya.

"PHP merupakan bahasa berbentuk skrip yang ditempatkan dalam server dan diproses di server. Hasil dari pemrosesan yang terjadi di server kemudian dikirim ke klien yang diakses melalui browser. PHP dirancang untuk membentuk aplikasi web dinamis yang artinya PHP dapat membentuk suatu tampilan berdasarkan permintaan terkini, seperti menampilkan isi dari suatu database" (Kadir, 2009).

PHP adalah pemrograman opensource yang digunakan untuk membuat sebuah aplikasi web dan dapat disatukan dengan HTML. Keunggulan PHP adalah sangat sederhana dan mudah dimengerti sehingga cocok untuk pemula maupun tingkat lanjut. Selain itu, karena PHP merupakan opensource maka
PHP dapat digunakan dibanyak sistem operasi (Cristianti \& Prakoso, 2008).

Jadi dapat disimpulkan bahwa PHP merupakan suatu bahasa pemrograman yang berbentuk skrip yang digunakan untuk mengolah suatu data yang ditempatkan dalam server dan mengirimkannya kembali ke web browser menjadi kode HTML.

Menurut Arief (2011), PHP adalah Bahasa server side scripting yang menyatu dengan HTML untuk membuat halaman web yang dinamis. Karena PHP merupakan server-side-scripting maka sintaks dan perintah-perintah PHP akan diesksekusi di server kemudian hasilnya akan dikirimkan ke browser dengan format HTML.

PHP sebagai alternatif lain memberikan solusi sangat murah (karena gratis digunakan) dan dapat berjalan diberbagai jenis platform. PHP adalah skrip bersifat server-side yang ditambahkan ke dalam HTML. PHP sendiri merupakan singkatan dari Personal Home Page Tools. Skrip ini akan membuat suatu aplikasi dapat diintegrasikan ke dalam HTML sehingga suatu halaman web tidak lagi bersifat statis, namun menjadi bersifat dinamis. Sifat server side berarti pengerjaan skrip dilakukan di server, baru kemudian hasilnya di kirimkan ke browser. Sintaks dasar PHP meliputi bagaimana cara memulai suatu struktur pemrograman PHP.

\subsection{Rancangan Penelitian}

Penelitian ini merupakan sebuah studi kasus tentang Sistem Pendukung Keputusan penentuan Dosen Pembimbing Tugas Akhir menggunakan metode Analytical Hierarchy Process (AHP) di STMIK PPKIA Pradnya Paramita. berikut :

Tahapan Metode penelitian adalah sebagai

1. Identifikasi dan Analisis Kebutuhan. Kegiatan yang dilakukan pada tahap ini adalah melakukan observasi terhadap permasalahan yang sedang berjalan, studi literatur untuk mengetahui dan memahami dasar teori dan konsep-konsep yang mendukung dalam penelitian seperti buku, jurnal baik nasional maupun internasional serta melakukan wawancara dengan pihak yang terkait yaitu mahasiswa, dosen serta Ketua Program Studi.

2. Perancangan Sistem untuk penentuan dosen pembimbing. Berdasarkan identifikasi dan analisis kemudian merancang sistem dengan menggunakan (Data Flow Diagram) DFD untuk sistem pendukung keputusan penentuan dosen pembimbing dengan menggunakan metode AHP di STMIK PPKIA Pradnya Paramita.

3. Pembuatan Program Berdasarkan rancangan sistem yang telah dibuat kemudian diimplementasikan dengan menggunakan bahasa pemrograman Hypertext Prepocessor (PHP). 


\subsection{Ruang Lingkup Penelitian}

Penelitian ini mencakup Sistem Pendukung Keputusan penentuan Dosen Pembimbing Tugas Akhir menggunakan metode Analytical Hierarchy Process (AHP) di STMIK PPKIA Pradnya Paramita Malang.

\subsection{Jenis dan Sumber Data}

Penelitian ini bersifat deskriptif kuantitatif, yang bertujuan untuk menggambarkan dan mengungkapkan suatu masalah, keadaan, peristiwa sebagaimana adanya atau mengungkap fakta dari Sistem Pendukung Keputusan penentuan Dosen Pembimbing Tugas Akhir menggunakan metode Analytical Hierarchy Process (AHP) di STMIK PPKIA Pradnya Paramita Malang.

\subsection{Teknik Pengumpulan Data}

Teknik pengumpulan data dalam penelitian ini adalah dengan wawancara, observasi dan pembagian angket. Hal ini dilakukan untuk melengkapi pembahasan, berikut teknik pengumpulan data yang dilakukan:

\section{Wawancara}

Wawancara dilakukan terhadap pengguna di tingkat direktorat dan manajemen kampus penyelenggara. Hal ini dilakukan untuk mendapatkan informasi berkaitan dengan operasional pemilihan dosen pembimbing tugas akhir di STMIK Pradnya Paramita Malang.

2. Observasi

Untuk lebih mendapatkan gambaran tentang operasional Sistem Pendukung Keputusan Penentuan Dosen Pembimbing di STMIK pradnya paramita Malang.

3. Kuisioner

Pengumpulan data dilakukan dengan memberikan kuesioner kepada responden dari tingkat mahasiswa, pelaksana operasional sistem informasi dan top manajer. Kuesioner berupa indikator dalam penentuan dosen pembimbing.

\subsection{Teknik Analisis Data}

Berdasarkan data yang diperoleh dari wawancara dan kuisioner maka langkah selanjutnya adalah menganalisis dengan menggunakan metode AHP untuk penentuan Dosen pembimbing Tugas Akhir.

\subsection{Perancangan Sistem}

Perancangan dalam pembuatan sistem pendukung keputusan (SPK) penentuan Dosen pembimbing tugas akhir ini adalah berdsarkan tiga komponen utama dalam pembentuk SPK yaitu sub sistem manajamen model, sub sistem manajemen data dan sub sistema antarmuka pengguna. Pertama, dalam sub sistema manajemen model dalam SPK ini dengan menggunakan pendekatan terstruktur yaitu menggunakan data flow diagram (DFD). Seperti terlihat pada Gambar 3.

Berdasarkan Gambar 3 dalam sistem SPK penentuan Dosen pembimbing Tugas Akhir terdapat 2 entitas yaitu mahasiswa dan petugas BAAK. Selanjutnya, akan dilakukan proses dekomposisi atau detail dari proses DFD level 0 ke level 1, seperti pada Gambar 4.

Berdasarkan gambar 4 DFD Level 1 untuk pemilihan dosen pembibg tugas akhir terdapat 5 proses yaitu kelola data dosen, kelola kriteria, kelola rating, penentuan alternatif dan perhitungan AHP. Kedua, sub sistem manajemen data dalam SPK ini terdiri dari kriteria, bobot kriteria, rating, prioritas, topik, alternatif dan bobot global.

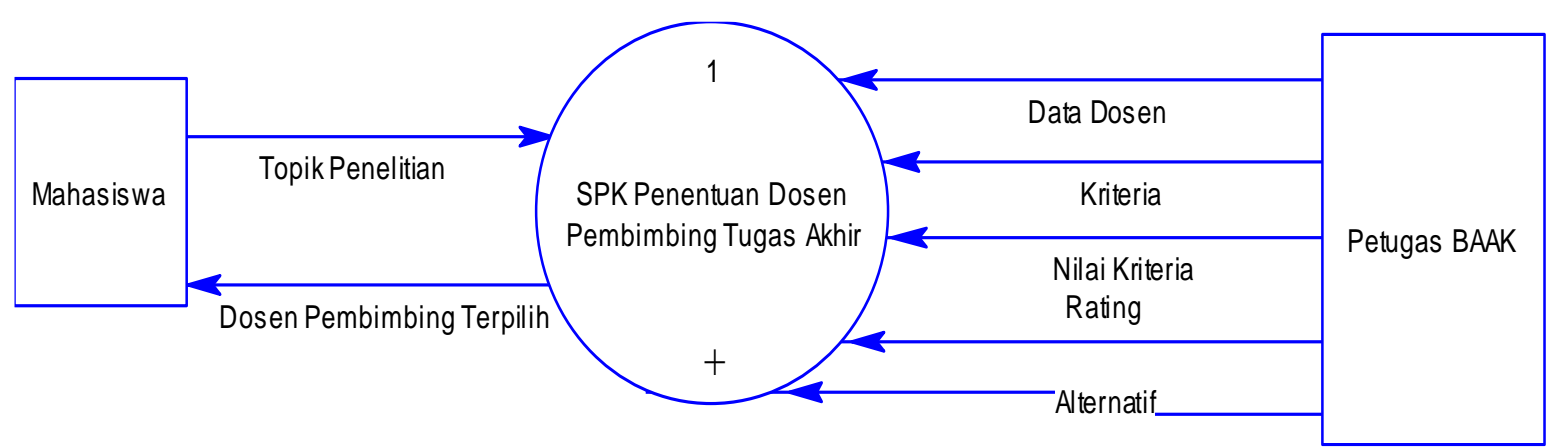

Gambar.3 Context Diagram atau DFD Level 0 Pemilihan Dosen Pembimbing 


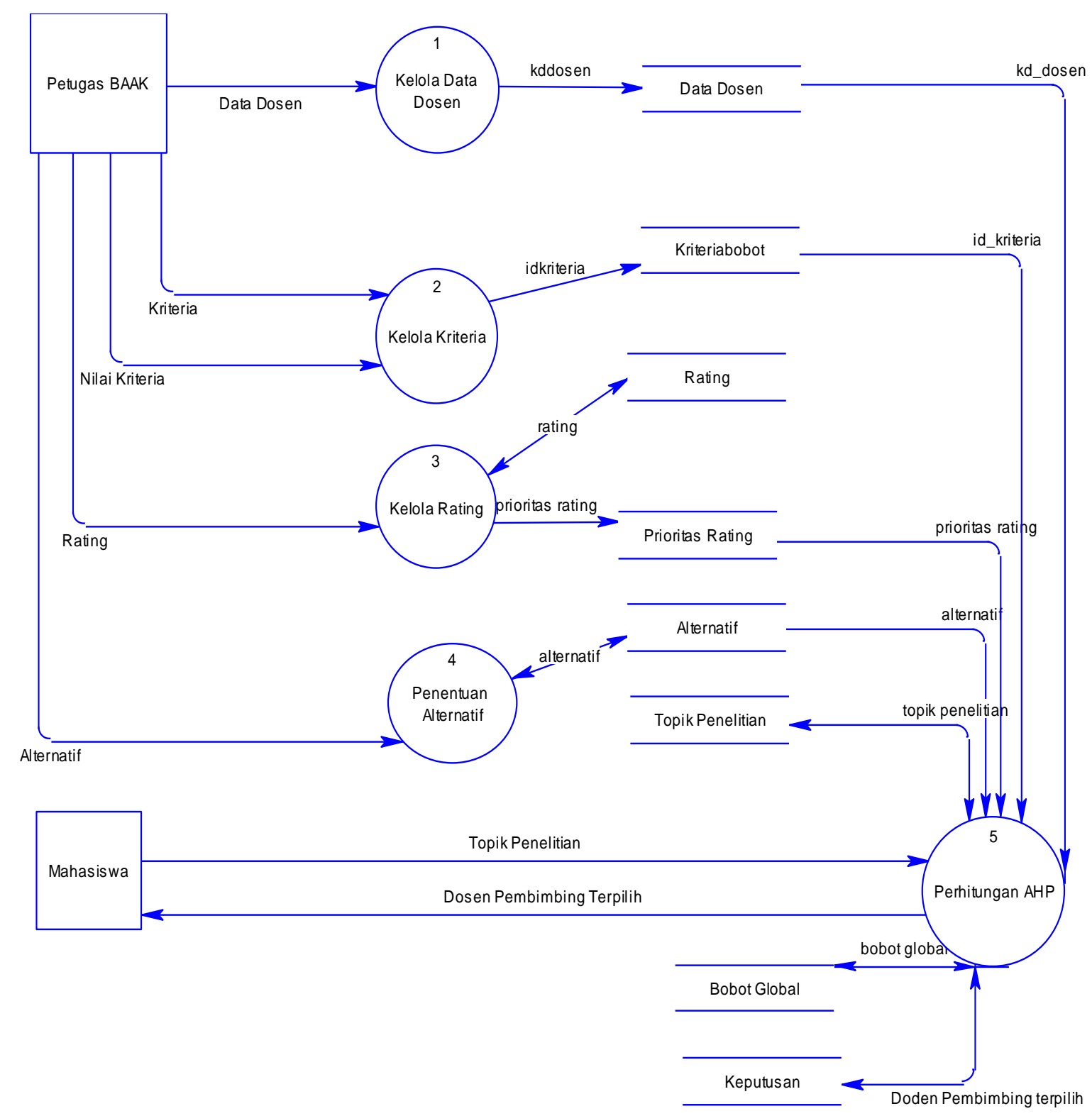

Gambar 4. DFD Level 1 Pemilihan Dosen Pembimbing

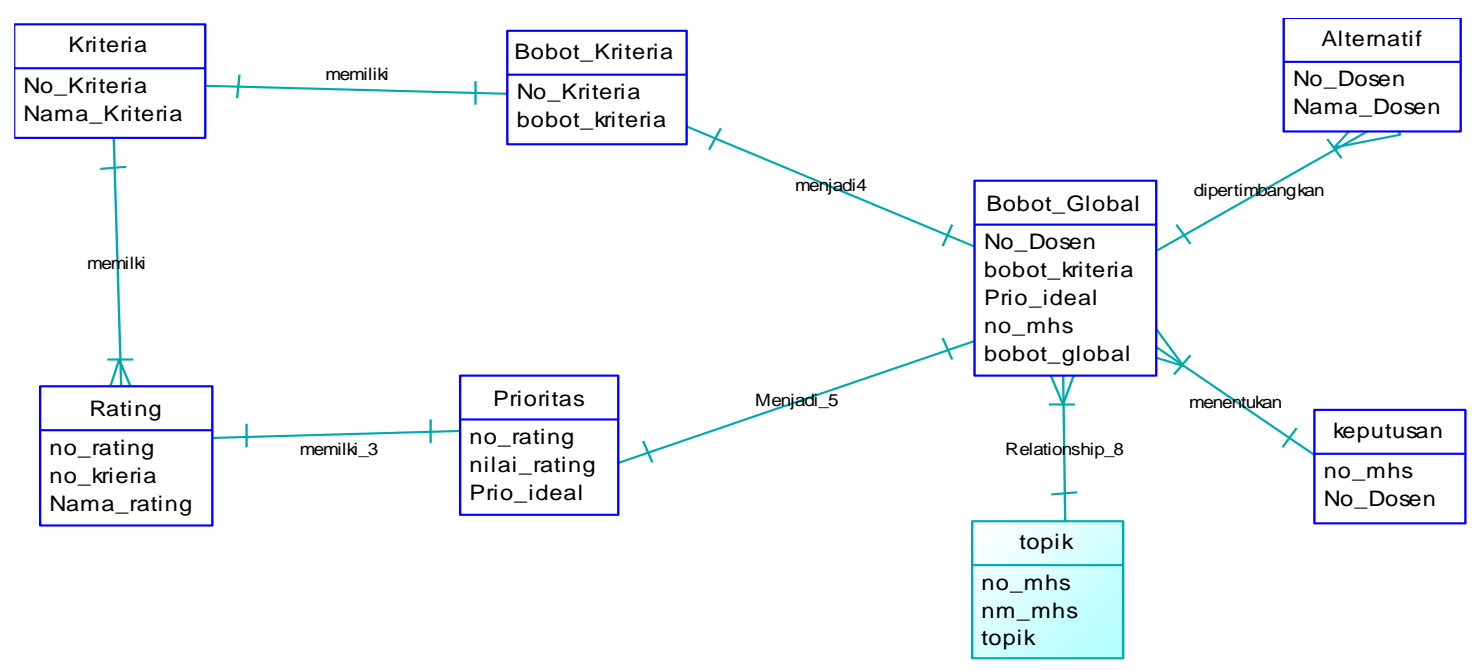

Gambar 5. Rancangan Database untuk SPK penentuan Dosen Pembimbing Tugas Akhir. 


\section{IMPLEMENTASI HASIL}

\subsection{Desain Antar Muka}

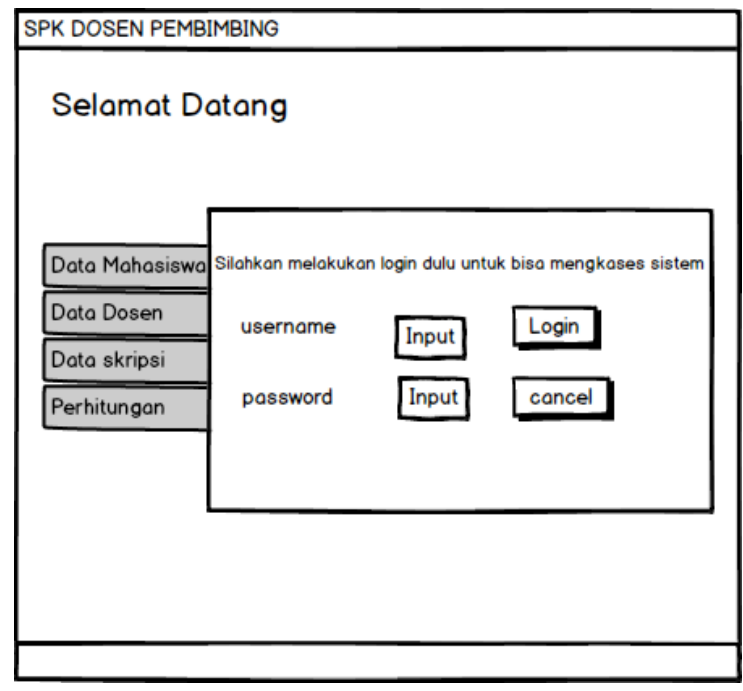

Gambar 6 .Halaman Utama

SPK DOSEN PEMBIMBING

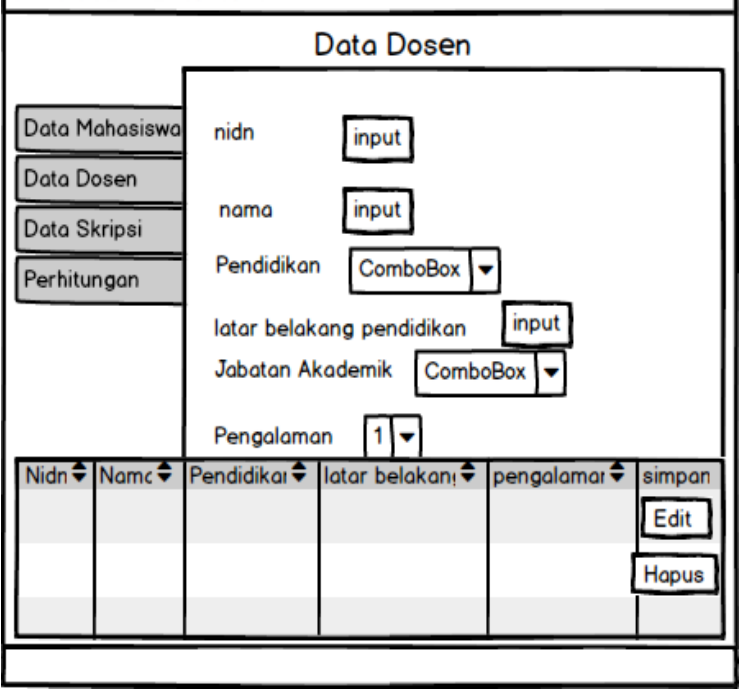

Gambar 7 .Master Data Dosen

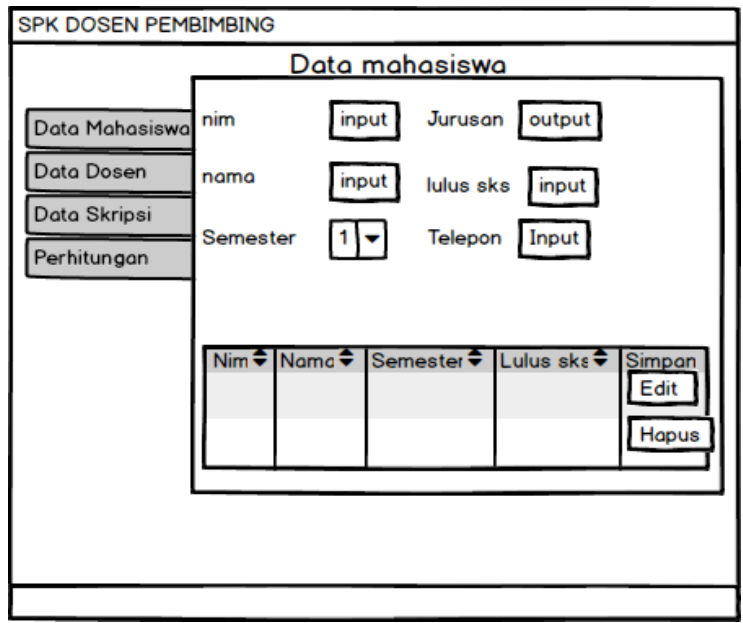

Gambar 8. Master Data Mahasiswa

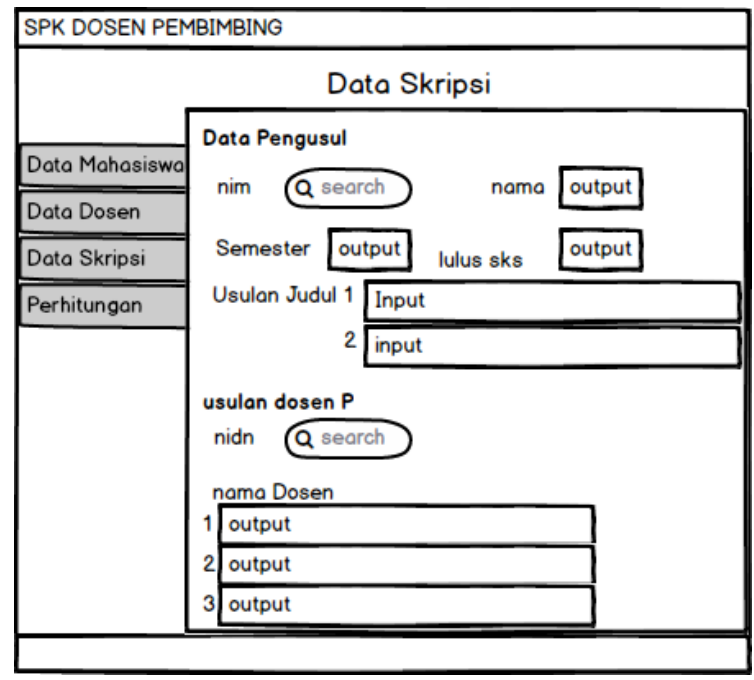

Gambar 9. Data Skripsi

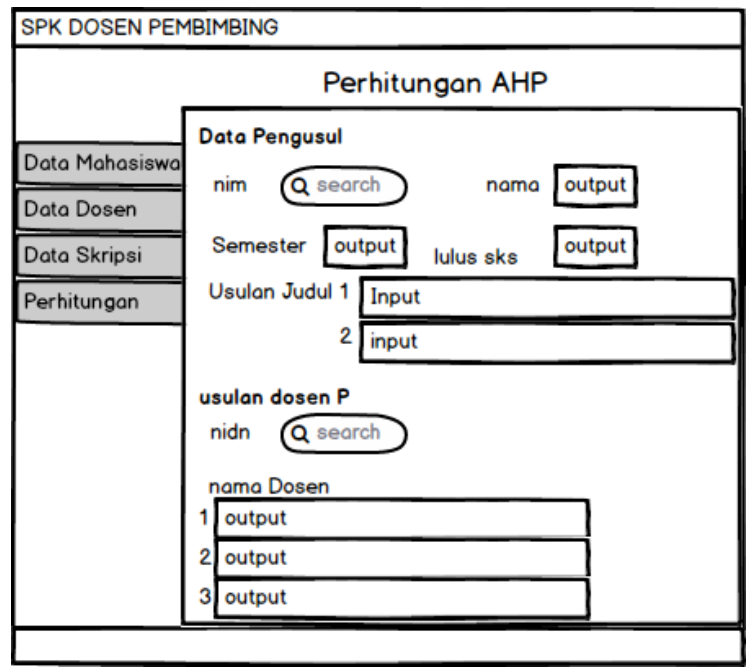

Gambar 10. Perhitungan AHP

\section{KESIMPULAN DAN SARAN}

\subsection{Kesimpulan}

Sistem pengambilan keputusan ini dapat membantu program studi dalam menentukan dosen pembimbing tugas akhir berdasarkan kriteria dan nilai pembobotan. Hal ini berguna untuk memudahkan pengambilan keputusan yang terkait dengan penentuan dosen pembimbing, sehingga akan didapatkan dosen pembimbing tugas akhir yang paling layak untuk membimbing mahasiswa sesuai core kompetensi program studi.

\subsection{Saran}

Berdasarkan penelitian ini, saran yang diberikan untuk pengembangan berikutnya adalah penerapan sistem SPK pada bagian BAAK, Agar pengambilan keputusan mengenai dosen pembimbing lebih cepat dan tepat sesuai dengan tema tugas akhir mahasiswa. 


\section{DAFTAR PUSTAKA}

Anhar. (2010). Panduan Menguasai PHP \& MySQL Secara Otodidak. Mediakita. Jakarta.

Cristianti, M., \& Prakoso, S.B. (2008). Analisis dan Perancangan Sistem Informasi Akademik Dengan Studi Kasus Pada Sekolah Menengah Atas Terpadu (SMAT) Krida Nusantara", Jurnal Sistem Informasi, 3(1)

Kadir, A. (2009). Mastering AJAX dan PHP. Penerbit Andi Offset.Yogyakarta

Kusrini. (2007). Konsep dan Aplikasi Sistem Pendukung Keputusan, C.V Andi Offset. Yogyakarta

Kustiyahningsih, Y. (2011). Pemrograman Basis Data Berbasis Web Menggunakan PHP \& Mysql. Penerbit Graha Ilmu .Yogyakarta

Mardison. (2012). Sistem Pendukung Keputusan Dalam Pencairan Kredit Nasabah Bank Dengan Menggunakan Logika Fuzzy Dan Bahasa Pemrograman Java. Jurnal Teknologi Informasi \& Pendidikan, 5(1).

Rosa, A.S., \& Shalahuddin, M. (2013). Rekayasa Perangkat Lunak Terstruktur Dan Berorientasi Objek. Penerbit Informatika. Bandung.

Rudianto, A.M. (2011). Pemrograman Web Dinamis Menggunakan PHP Dan Mysql. C.V ANDI OFFSET.Yogyakarta

Sinaga, A., \& Hasan, Y. (2015). Aplikasi Pendukung Keputusan Penentuan Dosen Pembimbing Skripsi S1 Teknik Informatika, 5(2) 